\section{Creatine-phospho-transferase Isozymes}

Proteins with the same enzymatic specificity which can be resolved into different molecular forms by physicochemical techniques have been defined as isozymes by Markert and Møller ${ }^{1}$.

Such enzyme heterogeneity is a widely known phenomenon. Differences have been found between enzymes with the same substrate specificity in different species, in different tissues from the same species, and in adult and embryonic cells. In $1961 \mathrm{~K}$. F. Gregory stated that more than 30 enzymes were known to oxist in multiple molecular forms within individual organisms. The existence of more than one form of an enzyme within a cell has been considered as a biological principle.

We have boen successful in separating isozymes of creatine-phospho-transferase (CPT) according to the aforementioned definition.

Human tissues with high CPT activity aro heart and skeletal muscle and the central nervous system. A high activity in serum has been found in muscular disease.

Water extracts of heart-muscle and skeletal muscle and of brain tissue from human cadavers, and of human muscle obtained by biopsy have been made. Serum from patients with muscular dystrophy and with heart infaret has also been investigated.

The extracts of muscle and brain were made with ultrasonic vibration or in a Potter-Elvehjem apparatus.

The separations were performed with starch-gel electrophoresis according to Smithies ${ }^{2}$ and agar electrophoresis according to the principles of Wieme ${ }^{3}$.

The bands were made visible through reduction of nitro-blue-tetrazolium in the presence of $\mathrm{NADPH}_{2}$, which was generated essentially as in Oliver's method of CPT. measurement where creatine phosphate (CP) is used as the specific substrate ${ }^{4}$

When the separation was performed with starch-gel electrophoresis four bands were obtained dependent on the presence of the specific substrate (CP). The same number of bands was present in the different extracts and in serum from the different patients previously mentioned.

With agar electrophoresis of muscle and brain extracts we obtained only one band dependent on the prosence of

$A 1$

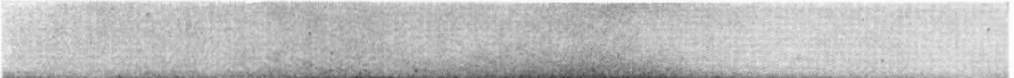

A2

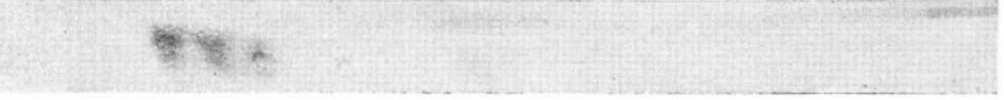

$\uparrow \uparrow \uparrow$

$B 1$

$B 2$
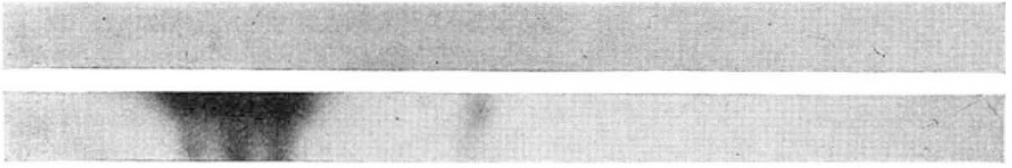

$\uparrow \uparrow \uparrow$

$\uparrow$

$C 1$

$C 2$

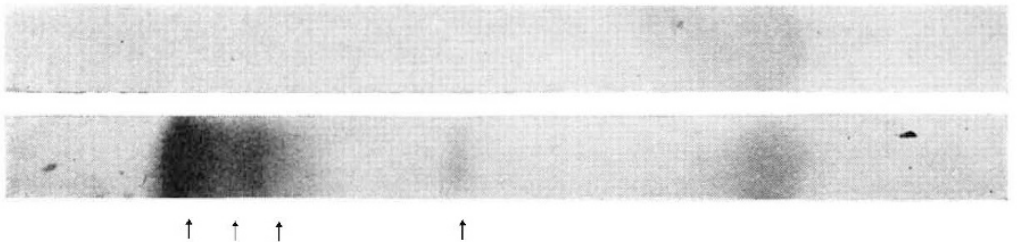

Fig. 1. Starch-gel electrophoresis. $A$, Serum from patient with heart infarct: (1) no ipecific substrate (CP) in the reaction mixture; $(2)$ complete reaction mixture. $B$, Serum from patient with dystrophia musculorum progressiva, type III: (1) no specific substrate (CP) in the reaction mixture, (2) complete reaction mixture. C, Fxtract fron reaction mixture
$A 2$

$B 1$

Fi
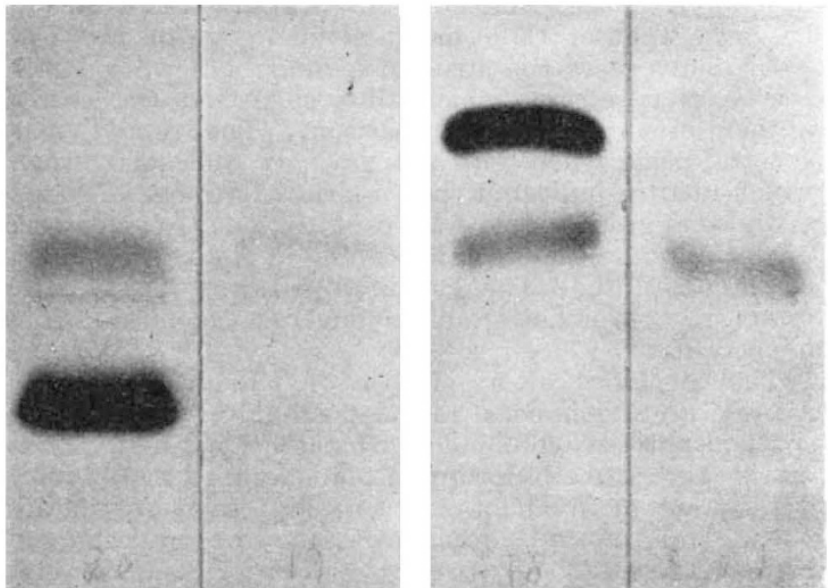

Fig. 2. Agar electrophoresis. $A$, Extract from skeletal muscle: (1) complete reaction mixture; (2) no specific substrate (CP) in the reaction $B$, Extract from brain: (1) complete reaction
(2) no specific substrate (CP) in the reaction mixture

the specific substrate. The respective band, however. moved in different directions.

Institute of Biochemistry,

KJell SJövalt

Central Laboratory,

Ann Volgt

iversity Hospital,

Markert, C. I., and Moller, F., Proc. U.S. Nat. Acad. Sci., 45, 753 (1959).

Smithies, O., Adv. Protein Chem., 14, 65 (1959).

Wieme, R. G., Clin. Chim. Asta, 4, 317 (1959).

$W_{E}$ have identified a number of previously unreported

\section{Volatile Hop Esters}

ester constituents of hops. The esters, identified rather positively by comparison of their mass spectral patterms and retention times with those of authentic samples, were 2-methylbutyl propicnate, 2-methylbutyl 2-methylbutyrate, hexyl propionate, hexyl isobutyrate, heptyl propionate, heptyl isobutyrate, octyl propionate and octyl isobutyrate.

An analysis of a whole hop oil using the combination of capillary gas chromatography and mass spectrometry $^{1,2}$ has been reported ${ }^{3}$. In the present analysis, the oxygenated frac. tion of the steam distillate of 1962 Brewers Gold hops was separated from the whole oil by chromatography on silica according to the method of Kirchner and Miller. This fraction was then analysed by the capillary gas chromatography and mass spectro. metry already mentioned.

In the work recorded here the gas liquid chromatography column was $290 \mathrm{ft}$. long by $0.0 \mathrm{I}$ in. internal diameter, stainless steel and coated with 'Tween-20'. It was manually" programmed non-linearly from $50^{\circ}$ to $200^{\circ}$ C. For gas liquid chromatography retention time measurements. the cupillary was led into a flame ionization detector. The carrier gas was helium at a velocity of $16 \mathrm{~cm} / \mathrm{sec}$ 